\title{
The Challenges of the Implementation of Construction Robotics Technologies in the Construction
}

\author{
Mohd Yamani Bin Yahya, Lee Hui Yin, Azlina Binti Md. Yassin, Roshartini Omar, Rolyselra Orbintang anak Robin \\ and Narimah Kasim
}

Department of Construction Management, Faculty of Technology and Business, Universiti Teknologi Tun Hussein Onn

\begin{abstract}
Robotics is one of the advanced technologies that is used in various aspects of the construction industry to improve the efficiency and the performance of construction projects. The adoption of construction robotics technologies is significant strategies to maintain and improve productivity in the construction industry. Even though the implementation of construction robotics technologies can improve productivity, many Malaysian contractors do not embrace the existence of robotic technology and still practicing the traditional method due to many challenges. Therefore, the objectives of the study were to investigate the challenges of the implementation of construction robotics technologies in the Malaysian construction industry and the improvement method. The data of the research were achieved through a quantitative method, which questionnaires were distributed to 180 G7 contractors in Kuala Lumpur. Subsequently, 50 valid responses were retrieved and the collected data were analysed using Statistical Package for Social Science (SPSS). The findings revealed that the two (2) main challenges of the implementation of construction robotics in Malaysia were the high cost to maintain and update process the technologies. The finding also showed that strategic partnership with a high technology company was the best method to improve robotics implementation. In conclusion, this study is believed to be useful information in improving the implementation of robotics technologies in construction projects particularly around Klang Valley.
\end{abstract}

\section{Introduction}

Robotics technology was first introduced to Japan by the United States in 1968 and plays an important role in the automation of factories [1]. Research in construction robotics started in the 1980 s with the introduction of single-purpose robots to perform specific jobs such as concrete finishing or welding and the main focus of the robots is to perform activities that are difficult, dirty or dangerous (3D) [1]. Robotics applications in the construction industry are designed and produced by in Japan by the big five companies which are Shimizu, Obayashi, Takenaka, Taiseiand Kajima and these robots are divided into four categories which are the robots for structural work, finishing or completion work, inspection works, and maintenance work [2].

In 1990s, large Japanese construction firms had introduced on-site factories for high rise buildings and also heavy temporary structure such as Sky Factory, The SMART (Shimizu Manufacturing system by Advances Robotics technology) System which are integrated with the automated construction system and has a weather protection cover that can utilize on a rainy day [3]. These structures using all-wheatear, full-robotic factory on the top of the buildings and lift-up the mechanism automatically raises the construction plant and raises the on-site factory in the same times [4]. The research and development (R\&D) activities lead by Japanese companies and universities that focusing on the development of new robotic systems and in the automation of existing machinery to automate several construction processes in the house building and civil construction [5]. For the house building, these robots were used for brick layered masonry, interior building finishing and modular industrialized building's construction. However, for the civil works including construction robots such as remote-controlled backhoes, bulldozers and dump trucks for disaster recovery and fully-automatic controlled shield machines [5]. The implementation of robotic technologies is divided into two perspectives which is off-site and on-site construction (Pachon, 2012).

According to [2] the Malaysian construction industry players are not aware of the existing of automation and robotics technology. Even that, new technologies had been introduced in the engineering, construction and design of the buildings [3]. Most of the construction players still practising the traditional method in their construction project [6]. This shows that lack of interest in robotic technology among the construction industry due to the unique nature of every 
project, production moving from the only location to another, divided authority over the process, rugged environment and volatile market [6], [7]. Hence, the main objectives of the research are to investigate the challenges of implementation of construction robotics technologies in Malaysia and improve it application.

\section{Literature Review}

\subsection{Construction Robotics Technologies}

The term robot was used by Czech playwright Karel Capek in his play 'Rossum's Universal Robots' performed in Prague in 1921. The term "robotics" was coined by Isaac Asimov in his 1941 science friction short-story 'Liar' [8]. Robotics is defined as the engineering science and technology of robots, and their design manufacture, application, and structural disposition and related to electronics, mechanical, and software [9]. International Federation of Robotics (IFR) define a robot as being a machine which can be programmed to perform tasks which involve manipulative and in some cases locomotive actions under automatic control. In 1979, the American Robots Association defined robots as a multifunctional operator which can be controlled by programs. It moves the materials, components, tools and other special apparatus through control programs to finish a series of work. Likewise, robotics also defined as the technology includes both design and construction of robots, but also computer systems for their control, sensory feedback, and data processing [10].

On the other hand, construction robotics is defined as a re-programmable, multifunctional manipulator designed to move materials, parts, tools or special devices through variable programmed motions for the performance of a variety of tasks occurring in production processes of the building industry [11]. In order to avoid ambiguities, the term manufacturing robots are referring to industrial robots that were used in manufacturing industries. As [11] mentioned that construction robots and manufacturing robots are two different families of industrial robots being used in different branches of industry. Basically, manufacturing robots and construction robots are different families in the set of industrial robots but both of the robots can have the identical anatomy, but the robot geometry and capacity differ as a function of the type of application [11].

In addition, [12] also explain that construction robots are different from industrial robots. Construction robots must move about the site because of the large size buildings; able to handle large components of variable size and, weight; function under adverse weather conditions, and are constantly exposed to dust and dirt on site. The construction robots require engines, batteries or motor and able to drive themselves [13]. There are six categories in construction robotics such as control systems, automated systems, earth-working equipment, sensor systems, heavy lifting equipment, or path planning systems which help to improve productivity and safety on construction sites [14].

\subsection{Challenges of the construction robotics}

There are many challenges of implementation of construction robots [15]. The challenges of implementation of construction robotics technologies had been divided into different categories as illustrated in Table 1.

Table 1. The challenges of implementation of construction robotics.

\begin{tabular}{|l|l|}
\hline \multicolumn{1}{|c|}{ Challenges } & \multicolumn{1}{c|}{ Authors } \\
\hline Cost & {$[2],[17]$} \\
\hline $\begin{array}{l}\text { Incompatibility of } \\
\text { the technologies }\end{array}$ & {$[2]$} \\
\hline $\begin{array}{l}\text { Nature of } \\
\text { construction } \\
\text { industry }\end{array}$ & {$[2],[16]$} \\
\hline $\begin{array}{l}\text { Technological } \\
\text { usability }\end{array}$ & {$[4],[2],[16]$} \\
\hline $\begin{array}{l}\text { Technologies } \\
\text { adoption by } \\
\text { workers }\end{array}$ & $\begin{array}{l}\text { (Warszawski \& Sangrey, 1985; } \\
{[2]}\end{array}$ \\
\hline $\begin{array}{l}\text { Resources } \\
\text { Retraining of } \\
\text { workers }\end{array}$ & {$[2],[16],[17],[16]$} \\
\hline
\end{tabular}

Cost

High cost acquiring and maintaining the technologies is one of the challenges to implementation of construction robotics [2]. The high cost of the technologies implementation construction robotics where the automation technologies are so expensive [16]. The purchase and implementation of the technologies are costly that the firm which has a good turnover and market competition can only afford these technologies [17], In addition, the automation technologies need to updated and maintained and most of them are expensive to update and maintain [16]. Maintenance cost for the new robotics equipment normally is higher because of the need for the special technician to do the maintenance job.

\section{Incompatibility of the technologies}

Incompatibility of the technologies with existing practices and current construction operations [2]. Workers prefer the former and proven solution instead of innovative methods and technologies due to the volatile and unpredictable nature of the construction environment [7].

\section{Nature of construction industry}

The problem of fragmentation is the project process whether conventional or modern methods of construction are used [18]. Fragmented nature of the construction industry inhibits the implementation of new technologies [2]. Development of construction robots are 
technologically difficult because of the nature of the construction work processes itself and to work in construction where the robots need to be robust, flexible, with high mobility and versatility [2].

\section{Technological usability}

Technologies are difficult to use and not easily understood due to the difficulties of the software[2]. The high sophistication of the robot control system becomes a more challenges parts to workers in the construction industry who are more low education workers [4]. Robotics technologies are sophistication to control especially of the programming procedure and very difficult introduction in the construction industry [4].

\section{Technologies adoption by workers}

Technologies are not easily accepted by workers in the working places. In some countries, active workers unions look upon these technologies as a way to replace the workers [2]. This can show that the implementation of robotics in the building must fully support not only of labour but also of management at all levels in order to bring the expected results [7]. For example, In Australia, any attempt to introduce robots on to a construction site must be based on three-way negotiation between the men, management and the union where building union representative must be convinced the use of robots in construction will not threaten their jobs [2].

\section{Retraining of workers}

Most of the workers in the construction industry are foreign which consists of $93 \%$ are low-skilled labour [19]. So that, re-training of construction workers becomes a compulsory to upgraded skills for a semiskilled worker or through seminars and workshops to increased understanding of the technologies in the industry and on the worksites [16]. Training problem provides to the employees to interact with the new robotic equipment which will take time and cost a lot of money in the financial output [21]. Special training for the workers to operate the robots and the contractor must invest heavily in training and educate the workers [15].

\section{Resources}

The difficulties of implementation of construction robotics due to the high cost and only companies which have a good turnover and market competition can afford these technologies [17]. Limited resources available to the medium and small-sized firms to adopt these technologies because every construction process is unique in character and same technologies are not appropriate for all condition. Large companies have enough investments to inculcate new technologies as compared to small and medium firms [17].

\section{Methodology}

A quantitative method was adopted in this research and questionnaires were distributed to the selected companies in Kuala Lumpur. Total 180 sets of questionnaire were distributed to the respondents from
September 13th, 2017 until October 22nd, 2017. Questionnaires were distributed using Google forms which can help the researcher to collect the information quickly. The questionnaire was based on 5-point Likert Scale and was first piloted to 8 respondents for comments and suggestion. The questionnaires were sending randomly based on the G7 contractor company's email. Some of the respondents request to delete the question about the annual revenue company and add one column for respondents fills in others technology that they used. The review made were noted and taken into consideration during the modification of the question. In the end, an index means was used in order to get the range in each answer for achieving the research objectives.

\section{Data Analysis and Discussions}

\subsection{Return rate}

A total of 180 questionnaires were distributed to the G7 construction companies in Kuala Lumpur, Malaysia. Subsequently, 50 responses were received out of the total of 180 sent out, which translates to a response rate of $27.78 \%$. According to [21] the acceptable useable response rate using self-administered questionnaires is normally $25 \%$ to $35 \%$.

\subsection{Demographic Information}

The study's respondents represented professionals in the construction industry. They were engineers, project managers, site supervisors, and quantity surveyors which consist of $28 \%, 24 \%, 16 \%$ and $10 \%$ respectively. Likewise, contractors and executive directors consist of $6 \%$, architects, and safety officers consist of $4 \%$ and treasury managers consist of $2 \%$.

\subsection{Challenges of the implementation of construction robotics technologies in Malaysia}

Ten statements relating the challenges of implementation of construction robotics technologies was listed and presented in Table 2.

Table 2 showed the majority of the respondents strongly agreed that maintenance costing to be the main challenges of the implementation of construction robotics technologies in Malaysia. Followed by the cost to update the technologies was ranked second and the third was a high cost to acquire the construction robotics technologies. The results were different from previous research which stated that the cost to acquire the technologies as the top challenges [2]. However, 9 years had passed since the research had been conducted as recent research by [16] mentioned that the automation technologies were expensive to update and maintain. The maintenance cost for the new robotics technology is more costly because of the need for the special technician for the maintenance job. Only the companies who have a good turnover and market competition can 
afford these technologies due to the high cost of owning and operating automated technologies [17].

Table 2. Ranking of the Challenges of the implementation of construction robotics technologies in Malaysia

\begin{tabular}{|c|c|c|c|}
\hline No & Statement & Mean & Rank \\
\hline 1 & $\begin{array}{l}\text { High cost to maintain the } \\
\text { construction } \\
\text { technologies }\end{array}$ & 3.28 & 1 \\
\hline 2 & $\begin{array}{l}\text { High cost to update the } \\
\text { technologies }\end{array}$ & 3.24 & 2 \\
\hline 3 & $\begin{array}{l}\text { High cost of acquiring the } \\
\text { construction } \\
\text { technologies }\end{array}$ & 3.16 & 3 \\
\hline 4 & High cost to train the workers & 3.00 & 4 \\
\hline 5 & $\begin{array}{l}\text { High cost to re-training } \\
\text { workers with upgraded skills }\end{array}$ & 3.00 & 4 \\
\hline 6 & $\begin{array}{l}\text { Fragmented nature of the } \\
\text { construction industry }\end{array}$ & 3.00 & 4 \\
\hline 7 & $\begin{array}{l}\text { High sophistication of the } \\
\text { robot control system }\end{array}$ & 3.00 & 4 \\
\hline 8 & Finance constraint & 2.96 & 5 \\
\hline 9 & $\begin{array}{l}\text { Incompatibility of the } \\
\text { technologies }\end{array}$ & 2.88 & 6 \\
\hline 10 & $\begin{array}{l}\text { Workers are more prefer the } \\
\text { traditional method and proven } \\
\text { solution instead of modern } \\
\text { methods }\end{array}$ & 2.88 & 6 \\
\hline
\end{tabular}

Based on the results, respondents agreed that the cost to train the workers, re-training workers to upgrade skills, fragmented nature of the construction industry and high sophistication of the robot control system was ranked fourth. The need for a trainer to train the workers on how to handle the sophistication of the robot control system becomes a challenge for industry players. This is because $93 \%$ of workers in Malaysian construction industry are low-skilled labours [19].

In order to make the workers understand the operation the robotic technologies, training, and retraining of workers become compulsory to upgrade skills for semi-skilled workers in order to increase their knowledge for the robotics [16]. This will cause increase in time and cost. [20]. It is difficult to introduce high sophistication robot control system in construction site as workers were generally lower educated [22]. The fragmented nature does inhibit the implementation of new technologies but will bring a negative influence on the project performance which will be the challenges for the companies to adopt of the technologies [18].

Financial constraint was ranked fifth, Incompatibility with current practices and construction operations and workers prefer the traditional method and proven solution instead of the modern method were ranked sixth. A minority of respondents agreed, hence the low mean value. Due to the limited resources available to the medium and small sized firm were difficult to adopt these technologies because every construction process is unique in character and same technologies cannot be used all the time [17]. Most of technologies were not easily accepted by workers in the working places [2]. For example, the adoption of Industrialised Building System (IBS) was low due to the lack of skills and knowledge of the discipline among the workers who are more dependent to the conventional construction methods [23].

\subsection{Method to improve the implementation of the construction robotics}

Table 3. Improvement methods

\begin{tabular}{|c|l|c|c|}
\hline No & Improvement Method & Mean & Rank \\
\hline 1 & $\begin{array}{l}\text { Strategic partnership with high } \\
\text { technologies companies. }\end{array}$ & 3.32 & 1 \\
\hline 2 & $\begin{array}{l}\text { Incentives for Research and } \\
\text { Development (R\&D) }\end{array}$ & 3.20 & 2 \\
\hline 3 & $\begin{array}{l}\text { Incentives from government } \\
\text { Programme }\end{array}$ & 3.18 & 3 \\
\hline 4 & $\begin{array}{l}\text { Investment tax allowance } \\
\text { (ITA) for those companies that } \\
\text { use } \\
\text { technologies }\end{array}$ & $\begin{array}{l}\text { Incentives for training and re- } \\
\text { training workers }\end{array}$ & 4.14 \\
\hline 6 & $\begin{array}{l}\text { Development programs from } \\
\text { CIDB }\end{array}$ & 3.08 & 6 \\
\hline 7 & $\begin{array}{l}\text { Incentives for acquiring a } \\
\text { foreign company for high } \\
\text { technology }\end{array}$ & 3.04 & 7 \\
\hline
\end{tabular}

Table 3 depicted that majority of respondents agreed that strategic partnership with high technology companies was ranked as atop method to improve the implementation of construction robotics technologies in Malaysia. Strategies partnership will increase the technology transfer between two parties where the partnership can enhance the transfer of knowledge and technologies which can help the companies to expand their profit and performance. New technologies and skills may be transferred into the company and embedded into the business. For example, Sunway Group had taken advantages collaborates with Japanese developer Daiwa House Industry Co Ltd to complete projects by using prefabricated technologies. The partnership between each other will bring benefits where it will introduce the Daiwa' $s$ technologies into the region and can increase the $R \& D$ due to the technologies of Japan' s companies that utilize the advanced digital manufacturing and prefabrication technologies [24]. Hence, the companies who are taking partnership can grab more opportunity for more new projects.

An incentive for Research and Development (R\&D) was ranked the second method. As [25] mentioned that Malaysia' $\mathrm{s}$ awareness ofimplementation and consider research and development have to be part of the country' $s$ 
development still at low level. The incentive for Research and Development (R\&D) allow the companies can focus on the development of new robotics systems and in the automation of existing machinery.

An incentive from the government for programme was ranked as the third method to improve the implementation of construction robotics technologies.The government had introduced the Construction Industry Transformation Programme (CITP), 2016-2020, to propel the industry forward and meet the market demand [19]. This is followed by incentives for investment tax allowance can help to improve the implementation of construction robotics technologies where the allowance on qualifying plant and equipment acquired by the company during the ITA period can help to the company [26] The implementations of technologies were unattractive because it requires higher capital cost, and lack of support especially from clients towards the adoption of the technologies [27].

Hence, offering incentives such as tax breaks and loan facilities will be provided by the government to facilitate active economic growth (Zaihidee et al., 2014). The respondents agreed that the incentives for training and re-training workers also will improve the implementation of construction robotics technologies.

Soffar [20] found that the need for a training program to interact with the new robotics equipment will take time and cost. Education and training for Malaysian workers is also the priority as the new technology emerges[24]. This incentive will help the companies increase the efficiency of their work as all the workers had knowledge about how to use the technologies.

Respondents also agreed that development programs from CIDB were important to improve the implementation of construction robotics technologies. In order to increase productivity in the construction sector that focus on increasing of technology adoption, modernizing construction methods, CIDB will establish the center of excellence to become a one-stop center for technology adoption [19]. However, CIDB also collaborates with the global partnership to provide onsite support by providing workshop and seminars.

\section{Conclusion}

The cost to maintain the construction robotics technologies was the main challenges for the respondents to implement the construction robotics technologies. To overcome the challenges, the G7 contractors should make a strategic partnership with high technologies companies that have implemented construction robotics technologies in their organisations.

\section{References}

1. Cousineau, L., \& Miura, N. American Society of Civil Engineering (1998)

2. Mahbub, R. Unpublished Thesis, Queensland University of Technology, Australia (2008)
3. Kang, T.-K., Nam, C., Lee, U.-K., Doh, N. L., \& Park, G.-T. School of Electrical Engineering, pp 670-671 (2011)

4. Balaguer, C. Proceedings of International Symposium on Automation and Robotics in Construction (2004).

5. Arai, T. Construction, pp 3-7 (1994)

6. Nasir, S. R. M., Isa, C. M. M., \& Ali, K. Proceedings of the International Civil and Infrastructure Engineering Conference 2013, pp 16 (2014)

7. Warszawski, A., \& Sangrey, D. Journal of Construction Engineering and Management, vol. 111 no. 3), pp 260-280 (1985)

8. Saha, S. K. McGraw-Hill Education (2011)

9. Esakki et al, (2017)

10. Obdrzalek, R. D. University in Prague (2012)

11. Krom, R. TNO Building and Construction Research Robots in the Building Industry (1997).

12. Stein, J.J., Gotts, V. and Lahidji, B. [Online]. Available:

http://www.ent.ohiou.edu/ tscott/EECFG/ROBOTS. PDF (2002)

13. Vidyanagar, V. Engineering, 2 (2277), pp 76-78 (2013)

14. Son, H., Kim, C., Kim, H., Han, S. H., \& Kim, M. K. KSCE Journal of Civil Engineering, vol. 14 no. 2, pp 131-139 (2009)

15. Kumar, V. S. ., Prasanthi, \& Leena, A. IEEE Robotics and Automation Magazine, vol. 9 no. 1, pp 4-6 (2008)

16. Mistri, P. S., \& Rathod, H. Int. Journal of Advanced Research In Engineering, Science \& Management, pp 1-4 (2015)

17. Sadique, A., \& Mahesh, G. International Journal of Engineering Research and Science \& Technology, vol. 3 no. 1 (2016)

18. Nawi, M. N. M., Baluch, N., \& Bahauddin, A. Y. MATEC Web of Conference 15 vol. 9, pp. 1-8 (2014)

19. Economic Planning Unit (2015)

20. Soffar, H. [Online]. Available: https://www.onlinesciences.com/robotics/the-advantages-anddisadvantages-of-robots-in-the-factories/ (2015)

21. Fellows, R. and Liu, A. Blackwell Publishing (2003)

22. Gambao, E., \& Balaguer, C. IEEE Robotics and Automation Magazine, vol. 9 no. 1, p. 4-6 (2002)

23. CIDB Malaysia (2016)

24. Wong, K. The Edge Financial Daily (2014)

25. Zaki, S. M., S. F., \& Yusof, Z. M. International Journal of Sustainable Development (2010)

26. MIDA. (2012)

27. Khalfan, M. M. A., \& Maqsood, T. Journal of Construction Engineering, 